\title{
The Impact of Later Trading Hours for Australian Public Houses (Hotels) on Levels of Violence
}

\author{
TANYA CHIKRITZHS, P.G.DIP.HLTH.SC., ${ }^{\dagger}$ AND TIM STOCKWELL, PH.D. \\ National Drug Research Institute, Curtin University of Technology, GPO Box U1987, Perth, Western Australia 6845, Australia
}

\begin{abstract}
Objective: To examine the impact of later trading hours for licensed hotels (Australian public houses are usually known as "hotels") in Perth, Western Australia, on levels of violent assault on or near these premises. Method: Data on assault offenses reported to police between July 1, 1991, and June 30,1997, were examined to identify those offenses that occurred on or close to hotels. During this period, $45(24 \%)$ of the 188 hotels meeting study criteria were granted an extended trading permit for 1 AM closing ("ETP hotels"), whereas the rest continued to close at midnight ("non-ETP hotels"). A time-series analysis employing linear regression was used to test whether there was a relationship between the introduction of extended trading and monthly rates of assaults associated with ETP hotels, while controlling for the general trend in assault rates among normally trading hotels. Possible confounders and
\end{abstract}

other variables of interest (e.g., levels of alcohol purchases) were also examined. Results: After controlling for the general trend in assaults occurring throughout Perth hotels, there was a significant increase in monthly assault rates for hotels with late trading following the introduction of extended trading permits. This relationship was largely accounted for by higher volumes of high alcohol content beer, wine and distilled spirits purchased by late trading hotels. Conclusions: Late trading was associated with both increased violence in and around Perth hotels and increased levels of alcohol consumption during the study period. It is suggested that greater numbers of patrons and increased levels of intoxication contributed to the observed increase in violence and that systematic planning and evaluation of late trading licenses is required. (J. Stud. Alcohol 63: 591-599, 2002)
A USTRALIA HAS LONG BEEN a nation of beerdrinking "pub goers" and, as a result, the issue of trading hours for Australian public houses (usually known as "hotels") has frequently engaged both community and political interest (Room, 1988). The dominant "pub" environment of the pre-First World War era was once described as a "rollicking man's world of booze and two-up" (two-up is a traditional game of chance, in which bets are placed on the outcome of a two-coin toss), combined with record high rates of public drunkenness and nightly violence (Room, 1988). After more than 30 years of agitation, the traditional man's drinking world succumbed to the pressure of the temperance movement and, eventually, the "most far-reaching and visible restriction on drinking, the requirement of six o'clock closing for all alcohol sales, was adopted during the First World War" (Room, 1988, p. 16).

Contrary to expectations, the effect of the early closing time was to create a single hour of frantic drinking in Australian hotels. Between the end of the work day at $5 \mathrm{PM}$ and hotel closing time at $6 \mathrm{PM}$, great numbers of drinkers would clamor to the bar with the aim of imbibing as much alcohol as was possible in the short amount of time. This dramatic display of heavy drinking was colorfully described as the "six o'clock swill" (Room, 1988).

\footnotetext{
Received: August 29, 2001. Revision: March 6, 2002.

${ }^{+}$Correspondence may be sent to Tanya Chikritzhs at the above address, or via email at: T.N.Chikritzhs@curtin.edu.au.
}

The six o'clock swill effect is often cited as evidence that hotel closing hours should be more liberal and unrestricted, although in most states trading hours for hotels have been progressively lengthened over a number of years. During parliamentary debate of the New South Wales Liquor Act in 1982, it was recommended that extended trading be introduced in licensed premises, with the explicit reasoning that doing so would reduce heavy episodic drinking (Craze and Norberry, 1995). With reference to public health and order, the Australian Capital Territory adopted a similar stance in its Liquor Control Act of 1985 by stressing the need for extended trading hours and general deregulation of the liquor industry (Craze and Norberry, 1995). In Western Australia, the Liquor Licensing Act of 1988 stipulates closing times for licensed premises but permits an application to be made to the Director of Liquor Licensing for an extended trading permit (ETP) that generally allows an hour of extra trading at closing times (Liquor Licensing Act, 1988). In that state, there are no formal criteria for granting a late trading license; it is left entirely to the discretion of the Director of Liquor Licensing.

\section{Late trading and alcohol-related harm}

It has been argued by proponents of extended trading that the effect of longer drinking hours is to reduce an individual's overall alcohol consumption (i.e., that the increased drinking time allows drinkers to "pace them- 
selves" rather than succumb to the "swill effect") (Raymond, 1969).

It has also been argued that extended trading prevents the mass exiting of patrons at a single closing time, enabling police to better control and patrol high-risk areas at high-risk times (Marsh and Kibby, 1992). In an effort to reduce street violence in The Netherlands, various localities allowed premises to determine their own trading hours, thereby staggering closing times among the different premises and creating an environment in which alcohol was almost continuously available. Police authorities noted reductions in the levels of public disorder brought about by patrons exiting licensed venues en masse and by patrons moving between early and late closing venues (Marsh and Kibby, 1992), a phenomenon that tends to occur between hotels and nightclubs (Stockwell et al., 1992).

Chikritzhs et al. (1997a) conducted a study of 20 matched pairs of hotels in Perth, Western Australia, between mid1991 and mid-1995. Half of these gained ETPs in 1993-94 (hotels were matched on levels of assault prior to the introduction of late trading and wholesale alcohol purchases). The authors found that levels of monthly assaults associated with hotels that had ETPs more than doubled from mid-1991 to mid-1995, whereas there was no change for hotels with normal hours. They also found that levels of wholesale alcohol purchases increased dramatically among hotels that gained ETPs but found only modest increases for normally trading hotels over the same time period.

Chikritzhs and colleagues (1997a) failed to show any significant increase in road traffic accidents due to ETPs. In general, it has been difficult to show consistently any significant increases in overall levels of crashes, across studies, following extensions to trading hours (although only a handful of studies have been conducted). Chikritzhs et al. (1997a) and Smith (1988a), for example, found no overall increases in crashes, whereas Smith (1988b) showed persuasive evidence of an increase in crashes in Victoria following a change in hotel trading hours from 6 PM to 10 PM. The timing of traffic accidents (as well as violent assaults), however, has been reliably shown to shift, concurring with later closing times, with frequencies peaking shortly thereafter (Chikritzhs et al., 1997a; Lang et al., 1990).

The relationship between extended trading and individual levels of patron intoxication also is not clear. The majority of studies that have attempted to investigate the relationships between extended trading, alcohol-related harm and consumption levels have been unable to quantify directly individual levels of alcohol consumption or patrons' blood alcohol concentrations. The majority of these investigations have failed to show any significant increases in community consumption levels following changes in trading hours (e.g., Duffy and Plant, 1986; Goddard, 1986; Knight and Wilson, 1980).

A detailed study of the impact of extended trading hours in the city of Fremantle during the 1987 America's Cup found that those residents with high levels of consumption were more likely to take advantage of the opportunity to drink in hotels after midnight (McLaughlin and HarrisonStewart, 1988). Other researchers have drawn similar conclusions, arguing that drinkers already at high risk of alcohol-related harm (e.g., young people, and in particular young men, and the alcohol dependent) are also more likely to take advantage of the increased trading hours and are not inclined, or are less able, to regulate their drinking (Bennett, 1991; Smith, 1986).

\section{Extended trading permits in Western Australia}

In Western Australia, as of the implementation of the Liquor Licensing Act of 1988, it has been possible for hotels to apply for additional trading hours via a permit system known as the "extended trading permit" (ETP). At different times between 1989 and 1997, over 70 hotels in metropolitan Perth were permitted to trade for an extra hour after normal closing time (midnight). Not all hotels applied for an ETP, but the vast majority of those that applied were successful. All extensions were granted after June 1993. It was possible to combine this information with police data revealing the specific location of violent assaults officially reported between July 1991 and June 1997. It should be noted, however, that although officially reported assaults are a useful indicator of levels of violence, they are likely to make up only a small proportion of all incidents of violence that occur within a community (Homel et al., 1992). Thus, the combination of a distinctive Western Australian Licensing system and officially collected police data afforded the opportunity to test the impact of extended trading on levels of violence via a naturally occurring "experiment."

The main aim of this article was, therefore, to investigate whether extended trading affected levels of reported violence occurring in and around late trading hotels, when normal changes in levels of hotel-associated assaults were accounted for.

\section{Method}

Study design

This article describes the evaluation of a "natural experiment," employing Western Australian Police Service data on assault offenses collected between July 1991 and June 1997 and Liquor Licensing data on the granting of late trading in hotels. The main aim was to determine whether the overall monthly rates of assaults occurring in and around hotels that obtained ETPs at some time after mid-1993 were affected by the granting of late trading licenses. Regression analysis was applied to monthly timeseries data and included concurrent trends in monthly assault rates for normally trading premises, in order to control for 
trends unrelated to the granting of late trading licenses. Other possible confounders (e.g., average age and the proportion of male victims, changes to policing and community initiatives) were also controlled for in the regression analyses. Wholesale alcohol purchases of high and low alcohol content beverages were also examined for their effect on the association between ETPs and assault rates, in order to determine if alcohol consumption was a mitigating factor in the association between the two variables.

\section{Procedure}

Liquor licensing information and extended trading permits. Information regarding Perth metropolitan hotels with extended trading permits (ETPs) was provided by the Liquor Licensing Division of the Western Australian Office of Racing, Gaming and Liquor. Official data on the start date of all hotel liquor licenses as well as ETPs, hours and timing of extensions, terminations, suspensions, type of liquor license, annual wholesale alcohol purchases and license identification number were obtained. (Re-application for an ETP was required every 6-12 months; however, none of the ETPs included in this analysis was halted at any time during the study period. Once an ETP is granted, approval for continuation is largely assured, given that the primary liquor license remains active.)

Information specific to each hotel was used to identify which hotels had obtained an ETP and which had not. In addition, since primary liquor licenses may be terminated or suspended at any time, it was also necessary to identify which hotels had not operated continuously throughout the study period. Because it was not possible to accurately determine how long suspensions were in place, it was necessary to withdraw such premises from further analyses.

Discussions with key liquor licensing informants revealed that, upon receiving an ETP, many premises do not change their trading hours immediately but may take several months to implement the required staff and other changes. Moreover, the length of time available for analysis both before and after the start date of an ETP varies substantially among hotels. Preliminary examination of ETP start dates identified that some permits were only granted within a few months of the end of the study period (June 1997). For several hotels, therefore, too little assault data were available in order to derive reliable and stable assault rates. It was also noted that several hotels were only granted ETPs under strict conditions of conduct (e.g., the provision of substantial meals and entertainment).

Thus, in order to maximize the likelihood that actual changes in trading hours had occurred, to increase the reliability of comparisons and to provide as homogenous a group of late trading premises as possible, it was necessary to introduce further selection criteria specific to hotels with ETPs. For inclusion as ETP premises, a hotel was required to meet the following criteria: (1) have obtained an extension of trading hours that extended closing time; (2) have been granted an ETP between January 1, 1992, and December 31,1996 , so as to have at least 6 months of before and after assault data available for calculating reliable rates; (3) not include any special conditions (e.g., that require the mandatory provision of food with alcohol during the extended trading hours or make the ETP license intermittent or noncontinuous); (4) not have closed down for any undetermined or extended period of time.

All premises that gained an ETP at some time during the study period later applied for a continuation of the permit (all re-applications were granted). It can thus be reasonably assumed that, where granted, ETPs were utilized in every case.

All ETPs were granted after June 1993, but with start dates spread over the remainder of the study period. Figure 1 shows the number of hotels granted ETPs (left $y$ axis), as well as the percentage of all hotels operating with ETPs at monthly intervals (right $y$ axis), and identifies how they occurred gradually over time. In June 1993, the proportion of all hotels that had ETPs was zero; by June 1997, all 45 ETPs included in the study had been granted and were operational ( $24 \%$ of all hotels).

In order to determine the effect of the presence of late trading on assault rates, a dummy variable that delineated between a single "before" and a single "after" period was created. July 1993 marked the beginning of the after period. Since the introduction of ETPs was distributed over time, however, it was assumed that any impact would also have occurred gradually over time rather than all at once as of June 1993.

\section{Sample description}

Between July 1991 and June 1997, 244 hotel liquor licenses were in operation at some time in the Perth metropolitan area; $74(30 \%)$ obtained an ETP sometime after mid-1993. There were 56 hotels that did not meet the selection criteria for inclusion: 29 hotels that gained ETPS and 27 that only traded normally throughout the study period. Thus, a total of 188 hotels, $45(24 \%)$ of which obtained an ETP and $143(76 \%)$ that only ever traded normally during the study period, were included in the analyses.

Between July 1991 and June 1997, a total of 48,411 reported assaults occurred in the Perth metropolitan area. Over that time, the number of assaults increased by $60 \%$. The total number of assaults identified as associated with a hotel was 2,846 , approximately $6 \%$ of the overall metropolitan total. In 474 cases $(16.6 \%)$, however, it was not possible to precisely identify the name and location of the hotel. As a result, the total number of assaults recorded as associated with a specifically identifiable hotel $(n=2,372)$ represented $83 \%$ of the total number of known cases. Assaults on public officers $(3.5 \%)$ were not included in 


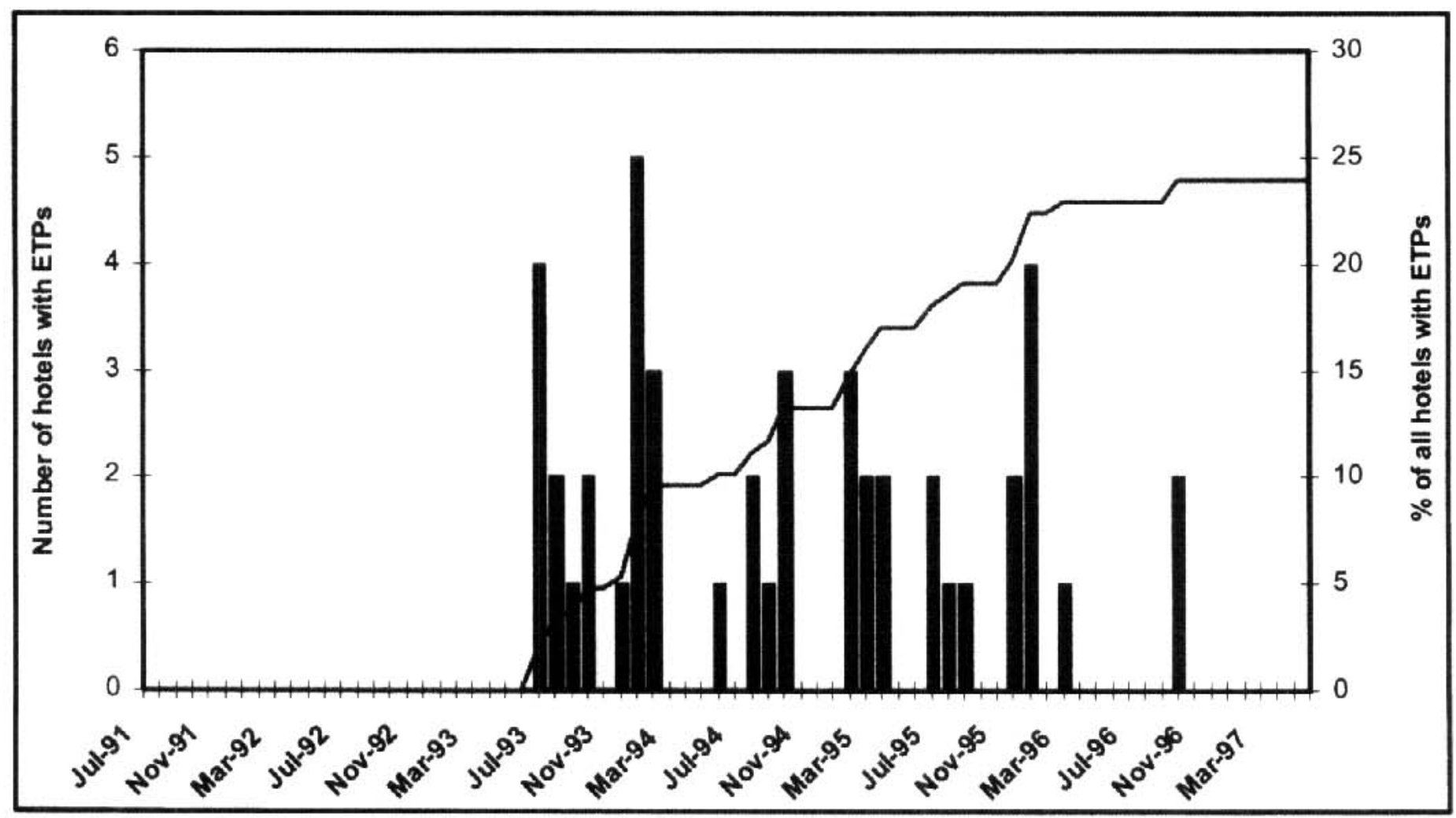

FIGURE 1. Number (bars) of hotels granted extended trading permits (ETPs) and percentage (line) of all hotels operating with ETPs, at monthly intervals from July 1991 to June 1997

any further analysis as they were likely to have been directly influenced by policing strategy and officer availability; the number of assaults was thus reduced to 2,289 .

The most frequently identified types of assaults associated with hotels were common $(47.7 \%)$ or bodily $(32.5 \%)$ assault. For the remaining categories (grievous bodily harm/ murder; wounding; sexual and indecent assault; assaulting a public officer; miscellaneous), numbers of charges were evenly distributed at about $4 \%$ of the total. For 13 reported cases of violence the assault charge was not available.

As shown in Table 1, after assaults associated with hotels ineligible for analysis (e.g., licenses suspended or terminated) were excluded, a total of 1,835 assaults remained, 544 of which were associated with ETP premises and 1,291 with normally trading hotels. Thus, excluding assaults involving a police officer and those associated with ineligible hotels, $79 \%$ of all reported assaults that occurred in or around hotels in the Perth metropolitan area between mid-1991 and mid-1997 were included in the following analyses.

As shown in Table 1, both ineligible groups of hotels had lower assault ratios per premises than their eligible counterparts. This was not surprising since they were largely eliminated from the study on the basis of inconsistent trading due to lengthy suspensions or termination of trading licenses.

\section{Location of holels with ETPs in the Perth metropolitan area}

ETPs were dispersed among 38 different post-code areas. As an overall ratio, there were two premises to every one post-code. Although similar to the overall ratio indicated for all hotels $(3: 1)$, the distribution of ETP premises among post-code regions indicated a greater concentration in city areas. It is notable that $31 \%$ of ETP premises were situated in inner-city areas, as opposed to $21 \%$ among all hotels.

\section{Control variables and possible confounders}

Changes in police operations. During 1996, some potentially significant changes in the policing of licensed premises occurred: (1) a "Zero Tolerance" program, introduced in April 1996, required all police officers to record all incidents of violent behavior and to pay particular attention to licensed premises; and (2) in the same year, police-licensee "accords" were introduced, which involved a greater physical presence of police around licensed premises. Accords aim to promote responsible server practices (e.g., checking patron identification to screen out underage drinkers, disallowing such drink specials as "happy hour," discouraging service to intoxicated patrons 
TABLE 1. Assault to hotel ratio for hotels with extended trading permits (ETP hotels) and normally trading hotels (non-ETP hotels) for those premises eligible and incligible for inclusion in analyses

\begin{tabular}{|c|c|c|c|c|c|c|}
\hline & \multicolumn{2}{|c|}{ ETP hotels } & \multicolumn{2}{|c|}{ Non-ETP hotels } & \multirow[b]{2}{*}{$\begin{array}{c}\text { Overall } \\
\text { total }\end{array}$} & \multirow{2}{*}{$\begin{array}{c}\text { Total } \\
\text { included } \\
\text { in } \\
\text { analyses }\end{array}$} \\
\hline & $\begin{array}{c}\text { Met } \\
\text { selection } \\
\text { criteria }\end{array}$ & Ineligible & $\begin{array}{c}\text { Met } \\
\text { selection } \\
\text { criteria }\end{array}$ & Ineligible & & \\
\hline No. hotels & 45 & 29 & 143 & 27 & 244 & 188 \\
\hline No. assaults & 544 & 299 & 1,291 & 155 & 2,289 & 1,835 \\
\hline $\begin{array}{l}\text { Assault to } \\
\text { hotel ratio }\end{array}$ & 12.1 & 10.3 & 9.0 & 5.7 & 9.4 & 9.8 \\
\hline
\end{tabular}

and drinking to intoxication). In response, police pledged increased officer presence in and around the participating area.

The impacts of these accords have been evaluated (Chikritzhs et al., 1997b; Hawks et al., 1999) and, although there was little evidence of their effectiveness, there was apparently an increase in police presence and an increase in reported violence around licensed premises. Given the tendency of ETP hotels to be more concentrated in innermetropolitan areas, this might have influenced recorded assault rates for ETP hotels toward the end of the study period.

In order to control for possible confounding, two dummy variables were introduced into the multiple regression model: (1) one called "zero tolerance," with a value of 0 until April 1996 and 1 thereafter, and (2) one called "accords," introduced as a positive value from December 1996.

Wholesale alcohol purchases. The Department of Liquor Licensing also provided information regarding annual wholesale alcohol purchases made by individual hotels from June 1990 to July 1997 . These data were used as a basis for calculating annual license fees and were scrupulously checked by the licensing authority against returns from wholesalers.

Access to wholesale purchase data of such precision provides a powerful tool for estimating consumption; however, it remains only a proxy measure of true sales figures. Insofar as there can be no distinction made between stockpiled or lost purchases and true sales, there can, in turn, be no certain assurance that all alcohol purchases were actually consumed by patrons. It is unlikely, however, that these shortcomings will affect the purposes for which the data have been utilized in this investigation. Moreover, any error is likely to be systematic, in which case it is reasonable to assume that all premises will be subject to similar degrees of estimation error.

Annual alcohol purchases made by each ETP hotel were categorized into high alcohol content beverages (high beer, high wine, distilled spirits) and low alcohol content beverages (low beer, low wine). For all the assaults that occurred in a particular month, the corresponding amount of alcohol purchased each year by the hotels in which the assaults occurred was summed, and then divided by the number of assaults. This allowed an indication of the level of high and low alcohol purchases made by the various hotels associated with any particular set of assaults for each month.

Analyses

Statistical analysis was done using multiple linear regression. The dependent variable was defined as the monthly rate of assaults associated with ETP hotels ("ETP assaults"). The main independent variable of interest was the dummy variable, "ETPs granted." Other possibly confounding variables controlled for in the analyses were the simultaneous monthly rate of assaults associated with normally trading hotels ("non-ETP assaults"); "zero tolerance" (includes increased police reporting and the Fremantle Accord); the Perth City Accord ("accord"); and annual wholesale alcohol purchases of "high alcohol" and "low alcohol" content beverages.

Preliminary examination of trends for ETP assaults, nonETP assaults and both beverage variables indicated the presence of some seasonal patterns, and all series were deseasonalized prior to analysis (multiplicative model used).

One of the major assumptions of multiple linear regression is that the residuals for the model must be free from serial autocorrelation. A Durban-Watson test of serial autocorrelation for the model with dependent variable "ETP assaults" and independent variables "ETPs granted" and "non-ETP assaults" fitted as regressors indicated that the residuals exhibited no significant positive $(d=1.935>$ $\left.d_{u, 0.05}=1.672\right)$ or negative $\left(4-d=2.065>d_{u, 0.05}=1.672\right)$ serial autocorrelation. In addition, examination of sample autocorrelation function plots of residuals did not reveal the presence of any nonseasonal spikes up to the 24th lag.

The primary regression model examined the linear association between ETPs granted and ETP assault rate, while controlling for the trend in non-ETP assault rates. The following regressions were designed to examine the strength of the association between ETPs granted and ETP assault rate, while adjusting for further possible confounders. Thus, second and third regressions determined whether it was necessary to adjust for mean monthly age of ETP assault victims and the proportion of men among ETP assault victims. The fourth and fifth regressions introduced the dummy variables for zero tolerance and the accord, respectively.

Further regressions introduced mean wholesale alcohol purchases of high and low alcohol content beverages so that their mediating effect on the relationship between ETPs granted and ETP assaults could be tested by measured changes in the standardized beta coefficient for ETPs granted. This is possible, since regression models provide coefficients for all variables in the model when all other variables are held constant. 
TABLE 2. Summary statistics for hotels with extended trading permits (ETP hotels) and normally trading hotels (non-ETP hotels) before and after the introduction of ETPs

\begin{tabular}{|c|c|c|c|c|}
\hline & \multicolumn{2}{|c|}{$\begin{array}{l}\text { ETP hotels } \\
\qquad(n=45)\end{array}$} & \multicolumn{2}{|c|}{$\begin{array}{l}\text { Non-ETP hotels } \\
\quad(n=143)\end{array}$} \\
\hline & Before & After & Before & After \\
\hline \multicolumn{5}{|l|}{ Assaults per hotel } \\
\hline Mean per month (year) & $0.121(1.452)$ & $0.187(2.244)$ & $0.112(1.344)$ & $0.133(1.596)$ \\
\hline $\mathrm{SD}$ & 0.064 & 0.072 & 0.038 & 0.034 \\
\hline $95 \% \mathrm{CI}$ & $0.094-0.148$ & $0.166-0.208$ & $0.095-0.128$ & $0.123-0.143$ \\
\hline Median per month & 0.112 & 0.196 & 0.115 & 0.134 \\
\hline Minimum per month & 0.023 & 0.056 & 0.033 & 0.057 \\
\hline Maximum per month & 0.239 & 0.357 & 0.220 & 0.212 \\
\hline Mean age of victims (yrs) & 24.64 & 28.99 & 25.79 & 28.85 \\
\hline $\begin{array}{l}\text { Mean proportion of male } \\
\text { victims }(\%)\end{array}$ & 71.90 & 77.50 & 69.02 & 76.53 \\
\hline
\end{tabular}

\section{Results}

Table 2 shows summary statistics for hotels with and without late trading both before and after ETPs were first introduced. Prior to ETPs being granted (Before period), monthly assault statistics for ETP and non-ETP hotels were similar, although there appeared to be more variability among monthly ETP assault rates than for normally trading hotels (see SD, Table 2). The mean age of victims and the proportion who were male were also similar for the two types of hotels in the Before period. Subsequent to ETPs being granted (After period), however, the mean monthly assault rate for ETPs increased by $54.5 \%$, whereas the rate for non-ETPs increased by only $18.75 \%$. The mean age of victims and the proportion of men who were victims also increased for both types of hotels in the After period.

Figure 2 shows the deseasonalized trends in monthly assault rates for both ETP and normally trading hotels between July 1991 and June 1997. Both trends appeared to increase after mid-1993. There was a more notable rise in rates for ETP hotels beginning about the second half of 1994, however, which was sustained to the end of the study period. At this time, approximately $10 \%$ of all hotels that were ever to obtain an ETP during the study period had been granted late trading (see Figure 1).

Preliminary histogram and normal probability plots of the deseasonalized dependent variable indicated a slightly positively skewed distribution, with little to be gained by transformation. All beverage variables, as well as age and gender, were symmetrical and approximately normally distributed and were not transformed.

A test of the linear relationship between ETPS granted and monthly assault rates for ETP hotels, while controlling for monthly non-ETP assault rates, indicated evidence of a significant positive linear relationship $(t=3.3,71 \mathrm{df}, p<$ $.01)$. The unstandardized beta coefficient for ETPs granted was 0.0595 and the adjusted $R^{2}$ was not large $(16.8 \%)$. Histogram and probability plots of the standardized residuals showed no indication of problematic errors.
As shown in Table 3, controlling for the mean monthly age of ETP assault victims had little impact on the adjusted $R^{2}$ of the model, with no evidence of a linear association with the dependent variable $(t=-0.901,71 \mathrm{df}$, Ns). The proportion of men among ETP assault victims also failed to explain any of the variance in ETP assault rates $(t=$ $0.295,71 \mathrm{df}, \mathrm{Ns})$. Both the introduction of zero tolerance ( $t$ $=1.486,71 \mathrm{df}$, Ns) and of the Perth City Accord $(t=$ $-0.706,71 \mathrm{df}, \mathrm{Ns})$ were nonsignificant. In sum, none of the additional regressors was able to explain variation in the dependent variable. Moreover, entering each of the above variables produced little change to the standardized beta coefficient for ETPs granted and, therefore, there was no reason to suspect any meaningful confounding influence on the association between ETPs granted and ETP assaults (Rothman, 1986). This was particularly important with regard to zero tolerance and the accord. These policies were suspected as possibly increasing reported levels of assault in and around ETP premises due to an increase in police numbers in city areas in which many ETP hotels are located. Therefore, excluding all noncontributing variables, the most parsimonious model for ETP assaults was as follows:

ETP assaults $=$ constant $+\mathrm{b}_{1} \mathrm{x}_{1}$, in which: ETP assaults $=$ monthly rate of assaults associated with ETP hotels; $x_{1}$ dummy variable for ETPs granted, $0=$ before period, $1=$ after period; $b_{1}=$ regression coefficient for $x_{1}$ after adjustment for non-ETP assaults; constant $=0.086$. If $x_{1}=0$, ETP assaults $=0.086+0=0.086$. If $x_{1}=1$, ETP assaults $=0.086+0.060=0.146$.

Thus, after adjusting for assault trends associated with normally trading hotels, the mean assault rate for ETP hotels after the introduction of ETPs was 0.146 assaults per hotel per month (about 1.752 assaults/hotel/year), an increase of approximately $70 \%$ on the Before period. Multiplied out by the 45 ETP hotels in the study, this translates into an average of about 78.84 additional assaults per year subsequent to ETP introduction. It should be noted, however, that the granting of ETPs was spread out over time 


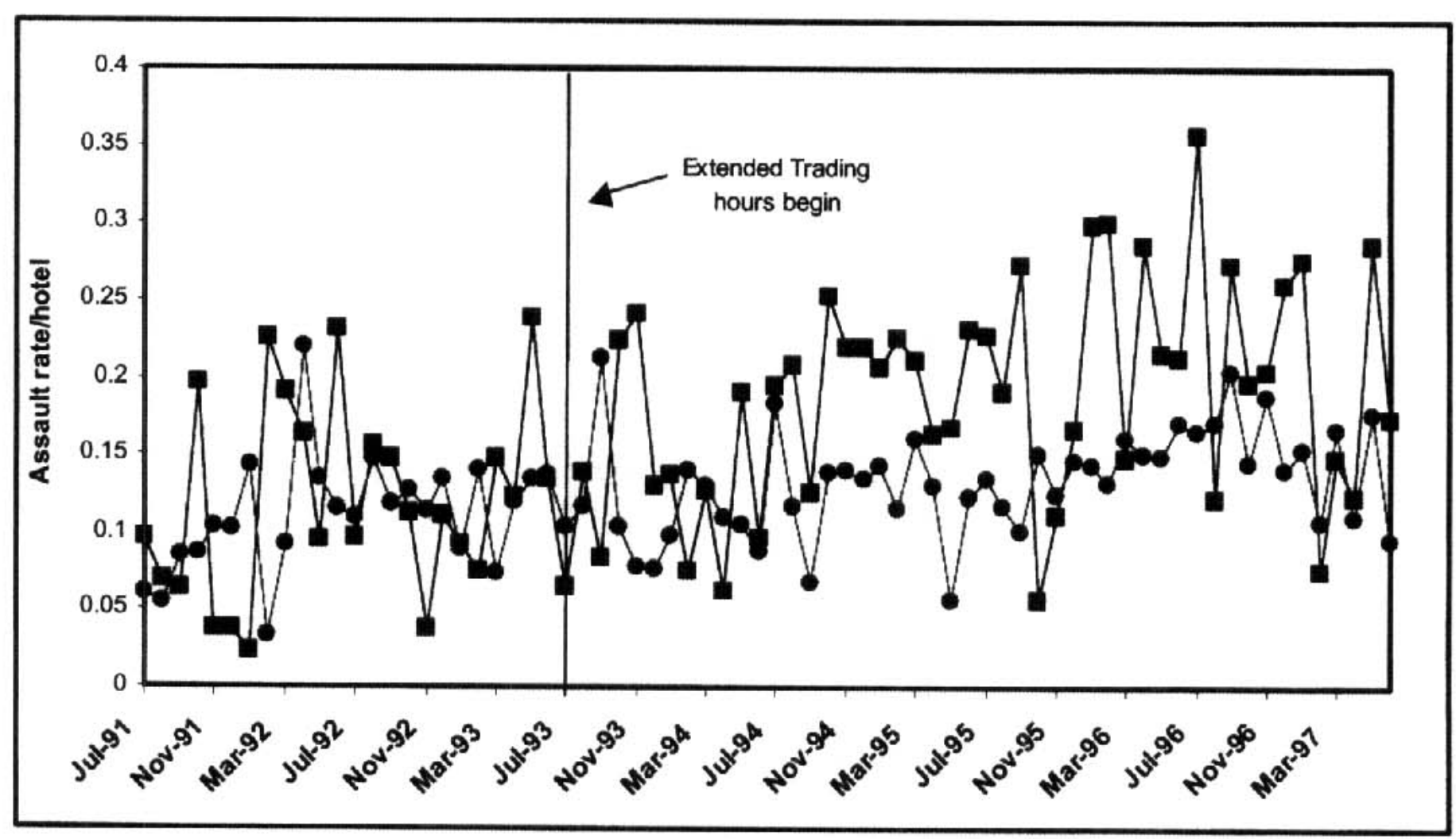

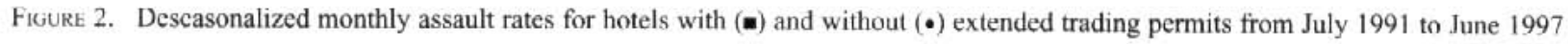

(see Figure 1); thus, the estimated change is only an approximate mean measure of the overall increase during the After period of the study. Moreover, officially reported cases of violence are estimated to be only a small proportion of the true levels of violence in a community and, hence, the results shown above are likely to be underestimated.

In order to determine whether the apparent association between ETPs granted and ETP assaults could be wholly or partly explained by corresponding changes to estimates of alcohol consumption, the deseasonalized wholesale alcohol purchase variables were entered into the final model, above. The inclusion of high alcohol content purchases in-

TABLE 3. Regression statistics for extended trading permit (ETP) hotel assaults (dependent variable) with standardized Beta coefficients for "ETPs granted" (primary independent variable) when potential confounding variables were entered

\begin{tabular}{lccc}
\hline Variable entered & $\begin{array}{c}\text { Adjusted } R^{2} \text { for } \\
\text { model when } \\
\text { variable entered }\end{array}$ & $\begin{array}{c}R^{2} \text { change } \\
\text { when variable } \\
\text { entered }\end{array}$ & $\begin{array}{c}\text { Stnd Beta Coct. } \\
\text { for ETPs granted } \\
\text { when variable } \\
\text { entered }\end{array}$ \\
\hline ETPs granted & 0.159 & - & 0.413 \\
Non-ETP assaults & 0.168 & 0.021 & 0.372 \\
$\begin{array}{l}\text { Victim age } \\
\text { Victim gender }\end{array}$ & 0.166 & 0.010 & 0.398 \\
$\begin{array}{l}\text { Zero tolerance } \\
\text { Accord }\end{array}$ & 0.154 & 0.001 & 0.392 \\
$\begin{array}{l}\text { High alcohol content } \\
\text { wholesale purchases }\end{array}$ & 0.169 & 0.026 & 0.361 \\
\hline
\end{tabular}

creased the adjusted $R^{2}$ of the model to $77.8 \%$, and the association between ETP assaults and high alcohol content beverage purchases was highly significant $(t=13.8,71 \mathrm{df}$, $p<.001$ ). What is more important, however, is that, when entered into the model, high alcohol content beverage purchases by ETP hotels had a strong mediating effect on the association between ETPs granted and ETP assaults, with the standardized beta coefficient for ETPs granted reduced by nearly $60 \%$ (declining from 0.372 to 0.151 ), but nevertheless remaining significant.

In contrast, due to a high level of collinearity between high and low alcohol purchases (VIF of 20), the adjusted $R^{2}$ remained virtually unchanged when low alcohol purchases were introduced. When the trend in low alcohol content beverage purchases by ETP hotels was entered into the model without the inclusion of high alcohol purchases, however, it was evident that its mediating effect on the association between ETPs granted and ETP assaults was more limited than that for high alcohol content beverage purchases. In this case, the standardized beta coefficient for ETPs granted was reduced by $39 \%$.

\section{Discussion}

The Extended Trading Permit system allowed by liquor laws in Western Australia has some interesting and unique features. Since mid-1993, over 70 ETPs have been granted 
at various times by the Director of Liquor Licensing. The permits typically allow an additional hour of trading at peak times (e.g., Friday, Saturday and Sunday nights), changing the normal closing time of midnight to that of $1 \mathrm{Am}$ of the following day. The low levels of monitoring of licensed premises during this period afforded the opportunity to evaluate the impact of small extensions of trading hours in licensed premises on levels of assault.

The results of this investigation demonstrated that between July 1991 and June 1997 there was a significant increase in the level of violent assault occurring in and around Perth hotels, which was associated with the introduction of extended trading permits as of mid-1993. Officially reported cases of violence are estimated to be only a small proportion of the true levels of violence in a community, however, and hence total numbers of assaults were likely to have been underestimated.

It was also shown that the increased levels of violence associated with late trading were due, in large part, to higher levels of wholesale purchases of high-strength beer, wine and distilled spirits made by these hotels. One of the main limitations of the study, however, was that it was not possible to establish whether the increase in wholesale alcohol purchases was solely the result of increased patronage attracted to late trading hotels because of the extended closing hours, or whether there had also been an increase in the amount of alcohol consumed by individuals. It is most likely that the estimated increase in consumption resulted from both greater numbers of patrons and greater levels of intoxication.

Increased patronage for some hotels also may have lead to greater levels of crowding that may, in turn, have contributed to increased levels of violence, not only within the hotel but also in the immediate vicinity (e.g., footpaths, where patrons queue and compete for limited transport services). Several studies have identified that one of the major situational factors that contributes to patron frustration and aggression in licensed environments is overcrowding (Homel and Clark, 1994; Graham et al., 1980).

Late trading has also been shown to shift the time at which alcohol-related events (e.g., road crashes and violent assaults) occur (Chikritzhs et al., 1997a). In a practical sense, the shift in the timing of alcohol-related incidents due to extended trading has implications for patron access to public transport and emergency services. Patrons leaving hotels with extended trading at closing time may find it difficult to access public transport, as the availability of buses, trains and taxis is reduced in the early morning hours. Emergency scrvices are also generally less well resourced after midnight and any increase in treatment required for alcohol-related injury (e.g., road trauma or assault-related injuries) will contribute to this burden.

The present study is unique among all other studies on late trading in that it was able to compare concurrent con- trol hotels that traded with normal hours with those that closed 1 hour later, while using premises-specific information on indicators of assaults and alcohol sales. The analysis was also able to control for the possible confounding effects of a reorganization in policing practices toward the end of the study period, although the results indicated that these changes had no bearing on recorded assault rates.

Since some hotels opt for extended trading whereas others do not, this self-selection process is likely to bring with it other features that are specific to such hotels. It was found, for instance, that a larger number of hotels with extended trading are located within the city, where they may attract a different type of clientele. Management styles of ETP hotels may also be more aggressive than are those of other hotels. Nevertheless, such measurable characteristics as the age and gender of patrons and levels of violence prior to extended trading being introduced were similar for both types of hotels.

It may be that when opening hours are extended other features of the hotel are also changed, as part of a wider business strategy. For example, the premises may be refurbished, the hotel may take on a new name, or management may introduce a new approach to entertainment, all in an attempt to revitalize or attract a different kind or greater numbers of clientele. Perhaps drink promotions and discounts are incorporated to increase consumption. The finding that sales of high-strength beer, wine and distilled spirits explained much of the association between ETPs and violence would suggest that, in any case, responsible alcohol service was unlikely to have been improved by the additional hours. Other studies have also found these types of beverages to be strongly linked to levels of violence in Australia (Stevenson et al., 1999; Stockwell et al., 1998). These findings have implications for an even greater need for responsible server practices where extended trading permits are in place.

Last, it needs to be recognized that the pattern of results might simply reflect a redistribution of high-risk drinking and drinkers and that there were greater concentrations of such at late trading hotels as the study period wore on. The overall increase in assaults reported to police might also have been due to independent changes in policing practices unknown to this study (other than zero tolerance). Even if this were wholly true, the pattern of results reported remains of great significance at the local level. Increased trading hours for a local hotel will result in increased levels of violence in the immediate neighborhood. These results suggest a need for systematic planning in identifying where and when (if at all) late trading permits should be allowed to operate, and a need for ongoing monitoring of the impacts of late trading licenses. In Western Australia, at least, there is currently no underlying principle that might otherwise help reduce or control levels of alcohol-related harm associated with licensed premises and borne by communities. 


\section{References}

BenNETT, M. Licensing laws and drinking. Brit. Med. J. 303: 472, 1991.

Chikritzhs, T., Stockwell, T. and Masters, L. Evaluation of the Public Health and Safety Impact of Extended Trading Permits for Perth Hotels and Night-Clubs, Perth, Western Australia: National Centre for Research into the Prevention of Drug Abuse, 1997a.

Chikritzhs, T., Woollmer, J. and Penna, F. Evaluation of the Northbridge Accord, Perth, Western Australia: Alcohol Advisory Council of Western Australia, 1997b.

Craze, L. AND Norberry, J. The objectives of liquor licensing laws in Australia. In: Stockwell, T. (Ed.) Alcohol Misuse and Violence: An Examination of the Appropriateness and Efficacy of Liquor Licensing Laws across Australia, Canberra, Australia: Australian Government Publishing Service, 1995, pp. 35-56.

DUFFY, J.C. AND PLANT, M.A. Scotland's liquor licensing changes: An assessment. Brit. Med. J. 292: 36-39, 1986.

Goddard, E. Drinking and Attitudes to Licensing in Scotland, London, England: Social Survey Division, Office of Population Censuses and Surveys, 1986.

Graham, K., Larocgue, L., Yetman, R., Ross, T.J. and Gustra, E. Aggression and barroom environments. J. Stud. Alcohol 41: 277-292, 1980.

Hawks, D., Rydon, P., Stockwell, T., White, M., Chikritzhs, T. and HEale, P. The Evaluation of the Fremantle Police-Licensee Accord: Impact of Serving Practices, Harm and the Wider Community, Perth, Western Australia: National Drug Research Institute, Curtin University of Technology, 1999

Homel, H. AND CLARK, J. The prediction and prevention of violence in pubs and clubs. Crime Prev. Stud. 3: 1-48, 1994.

Homfi, H., Tomsen, S. And Thommeny, J. Public drinking and violence: Not just an alcohol problem. J. Drug Issues 22: 679-697, 1992.

KNIGHT, I. AND WILson, P. Scottish Licensing Laws: A Survey Carried Out on Behalf of the Scottish Home and Health Department, Scotland, Edinburgh, Scotland: Social Survey Division, Office of Population Censuses and Surveys, 1980.
Lang, E., Stockwell, T. AND Lo, S. Drinking Locations of Drink-Driving Offenders in the Perth Metropolitan Area, technical report prepared for the Western Australian Police Department, Perth, Western Australia: National Centre for Research into the Prevention of Drug Abuse, 1990.

Lipuor Licensing Act 1988, Perth, Western Australia: Australian Government Publishing Service, 1988.

McLaughlin, K. and Harrison-Stewart, A. Evaluation Study of the Relaxation of Alcohol Licensing Laws for the Defence of the America's Cup, Perth, Western Australian: Alcohol and Drug Authority, 1988.

Marsh, P. And KIBBY, K.F. Drinking and Public Disorder: A Report of Research Conducted for The Portman Group by MCM Research, London, England: The Portman Group, 1992.

Raymond, A. Ten o'clock closing: The effect of the change in hotel and bar closing time on road accidents in the metropolitan area of Victoria. J. Aust. Road Res. Board 3 (10): 3-17, 1969.

Room, R. The dialectic of drinking in Australian life: From the rum corps to the wine column. Aust. Drug Alcohol Rev. 7: 413-437, 1988.

Rotнman, K.J. Modern Epidemiology, Boston, MA: Little, Brown, 1986.

SмIтH, D.I. Comparison of patrons of hotels with early opening and standard hours. Int. J. Addict. 21: 155-163, 1986.

SMITH, D.I. Effect on traffic accidents of introducing flexible hotel trading hours in Tasmania, Australia. Brit. J. Addict. 83: 219-222, 1988a.

SмIтH, D.I. Effect on casualty traffic accidents of the introduction of 10 $\mathrm{pm}$ Monday to Saturday hotel closing in Victoria. Aust. Drug Alcohol Rev. 7: 163-166, 1988b.

Stevensun, R.J., Lind, B. And Weatherburn, D. The relationship between alcohol sales and assault in New South Wales, Australia. Addiction 94: $397-410,1999$.

Stockwell, T., Masters, L., Philips, M., Daly, A., Gahegan, M., Midford, R. AND Phile, A. Consumption of different alcoholic beverages as predictors of local rates of night-time assault and acute alcohol-related morbidity. Aust. New Zeal. J. Publ. Hlth 22: 237-242, 1998.

Stockwell, T., Somfrford, P. and Lang, E. The relationship between license type and alcohol-related problems attributed to licensed premises in Perth, Western Australia. J. Stud. Alcohol 53: 495-498, 1992. 